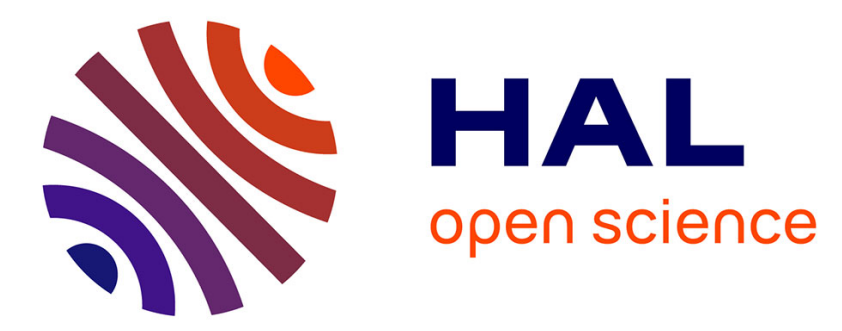

\title{
STEEL-18G2A AND STEEL-14HNMBCu STRENGTHENED BY EXPLOSIVE AND COLD-ROLLED DEFORMATION
}

J. Palczewski, J. Gronostajski

\section{- To cite this version:}

J. Palczewski, J. Gronostajski. STEEL-18G2A AND STEEL-14HNMBCu STRENGTHENED BY EXPLOSIVE AND COLD-ROLLED DEFORMATION. Journal de Physique IV Proceedings, 1991, 01 (C3), pp.C3-511-C3-518. 10.1051/jp4:1991372 . jpa-00250516

\section{HAL Id: jpa-00250516 https://hal.science/jpa-00250516}

Submitted on 1 Jan 1991

HAL is a multi-disciplinary open access archive for the deposit and dissemination of scientific research documents, whether they are published or not. The documents may come from teaching and research institutions in France or abroad, or from public or private research centers.
L'archive ouverte pluridisciplinaire HAL, est destinée au dépôt et à la diffusion de documents scientifiques de niveau recherche, publiés ou non, émanant des établissements d'enseignement et de recherche français ou étrangers, des laboratoires publics ou privés. 
Colloque C3, suppl. au Journal de Physique III, Vol. 1, octobre 1991

\title{
STEEL-18G2A AND STEEL-14HNMBCu STRENGTHENED BY EXPLOSIVE AND COLD-ROLLED DEFORMATION
}

\author{
J. PALCZEWSKI* and J. GRONOSTAJSKI** \\ *Military Institute of Engineering, ul. Obornicka 108, \\ PL-51-110 Wroclaw 43, Poland \\ ** Technical University of Wroclaw, ul. I. Lukasiewicza 3/5, \\ PL-50-371 Wroclaw, Poland
}

\begin{abstract}
Résumé : Dans l'article présenté, des résultats sur des aciers avec deux types de traitement thermique on été examinés : acier (18G2A) perlitique-ferritique et acier $(14 \mathrm{HNMBCu})$ sorbitique. Afin de prouver que les procédés d'élaboration conventionnels ne permettent pas l'utilisation complètes des propriété des matériaux, les deux aciers sont soumis à un écrouissage conventionnel (laminage à froid) et nonconventionnel (par explosif). L'influence du durcissement causé par les deux types de déformation est estimée et corrélée au chargement de la microstructure. Cette microstructure est étudiée par les microscopies optiques et électroniques à transmission et à balayage.
\end{abstract}

\begin{abstract}
In the presented paper were placed the results of examination of two differently heat-treated types of steel: ferritic-pearlite $/ 18 \mathrm{G} 2 \mathrm{~A} /$ and sorbitic $/ 14 \mathrm{HNMBCu}$. To prove, that the conventional manufacturing processes enable not fully the utilization of material properties the examined steels were subjected to the both conventional /cold-rolled/ and unconventional lexplosively/ plastic working. The effect of hardening caused by both kinds of deformation were estimated and it is correlated with structure changing. The structure was investigated by means of light, scanning and transmission microscopes.
\end{abstract}

\section{Introduction}

The characteristic feature of conventional plastic working processes is the required change of shape, the simultaneously improvement of material properties has not been usually taken into account. During the forming processes $2-10 \%$ of supplied energy is stored in the material. This energy should be utilized in forming processes to improve the mechanical properties of deformed materials $/ 2 /$. In the result it let to supersede more expansive materials for cheaper e.g. alloy steels for low-carbon steels. The best results can be obtained in unconventional manufacturing processes. One of these processes is the explosive hardening, which enable the required change of shape and considerably improvement of the material properties. The achievement of such results would be heavy or impossible. In general the explosive hardening is closed to near net-shape processes. At the small strain when the energy stored in materials is greatest the explosive hardening differentiates from conventional working, the explosive hardening let to obtain much greater hardening /3/. This can be explained by the facts, that the dislocation density is much higher for materials strained with higher strain rate and that the degree of strain hardening grows proportionally to the density of dislocations. In the conventional process the similar properties can be obtained by much greater strains. By the way to achieve the same hardness level in the aluminum alloy 20 24-T3 strengthened by shock wave, causing about $2 \%$ strain, it is necessary to strain to almost $30 \%$ by could-rolling $/ 1$. The simultaneously utilization of change of shape and of improvement of material properties demands the more complete study of different materials reactions with regard to their initial structure and kind of forming processes. 
bands come into existence both by dynamic and static load especially in low temperatures, when the slides are made difficult /4/. It was observed, that in such materials as low-alloy steel SAE 4130 and ferritic steels the grain size decrease reduces the twins number $19,12,13 /$. In loaded dynamically steels with ferritic-pearlite structure the strain twins appear in the whole kinds of ferrite. Hollingum $/ 14 /$ has proved, that twins were visible only in mild steel containing less than $0.2 \% \mathrm{C}$ in the steels containing more carbon and HSLA steels the twins were not formed. Similarly in the quenched and tempered steels it was not stated the twins presence. Usually can be stated, that twinning appearing particularly in the different systems causes the high material hardening and at further strain it causes the development of fractures. Therefore in the processes of plastic working strictly connected with the change of shape only should be avoided twins formation. It can be achieved by slowly prestrain of materials before the HERF working /high energy rate forming/ /15/ or by realization of the HERF process in the raised temperatures $/ 16 /$. It is not correct if the process HERF purpose is the hardening. The increase of deformation velocity during the explosive hardening can carry to the change of deformation mechanism, in which the twinning can dominate over the slides. In steels loaded with shock wave in the consequence of lattice distortion can take place the phase transformation $/ 3 /$. The new phase of hexagonal lattice is characterized by greater ratio of lattice parameters c/a. This phase is received from the BCC structure probably through the reduction of interatomic distance along the direction [001] and through the slide in the atomic plane $\{110\}$ in direction [110] or [101] /17/. The pressure value which causes the phase transformation is dependent on the chemical composition of steel. For low-carbon steels is needed pressure above 13GPa and for high manganese steel about 20GPa. From above mentioned bibliography it can be stated that the hardening effect dependent on types of created structure defects, their distribution and first of all their density. Even at the low pressure the dislocation density grows and the increase of pressure causes the further increase of density. At the higher pressure takes place the twinning. The fragmentation of grains and density of dislocation and twins determine the degree of hardening. The exceeding of the critical pressure value causes, that the phase transformation could be the fundamental mechanism of hardening. At high pressure the dislocation cellular structure is created and the partially recrystallization takes place, in consequence the hardening is less than obtained at slightly lower pressures $/ 3 /$. From the mentioned bibliography results, that there is the lack of comprehensive informations about the subject of explosive hardening of HSLA steels and the influence of the previous heat treatment on the hardening effect. The supplement of these informations the demonstration of advantages of unconventional processes of plastic working, the recognition of explosive hardening effects and the correlation of the effects with the structure, changes with regard to the initial state of steels were main aim of the below described tests.

\section{Experimental procedure}

In the investigation the two low-alloy steels: $18 \mathrm{G} 2 \mathrm{~A}$ and $14 \mathrm{HNMBCu}$ were used. The $18 \mathrm{G} 2 \mathrm{~A}$ steel was normalized in the temperature $1193 \mathrm{~K}$. The $14 \mathrm{HNMBCu}$ steel was subjected to quenching $1230 \mathrm{~K}$ and tempering $920 \mathrm{~K}$.

The dislocation initial structure of tested steels shows Fig.1, Fig.2 illustrates the kind and amount of non-metallic inclusions. The chemical composition and the mechanical properties were given in the Table1. The explosive hardening was realized with the linear pressure impulse using the plastic explosive MWP-8 with the density $1.35 \mathrm{~g} / \mathrm{cm}^{\wedge} 3$ and the velocity detonation $7300 \mathrm{~m} / \mathrm{s}$ in the direct system. In the experiment (Fig.3) the detonation front shifts tangent to the surface of the hardened plate. The hardened $16 \mathrm{~mm}$ thick plate (3) lies on the bottom plate (2) and this plate lies on the base plate (1) which lies on the base. The hardened plate (3) was covered with the foil PVC (5). On the foil 
a.

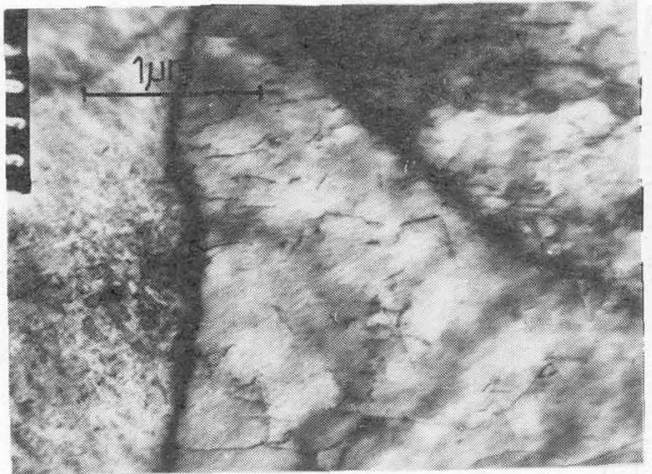

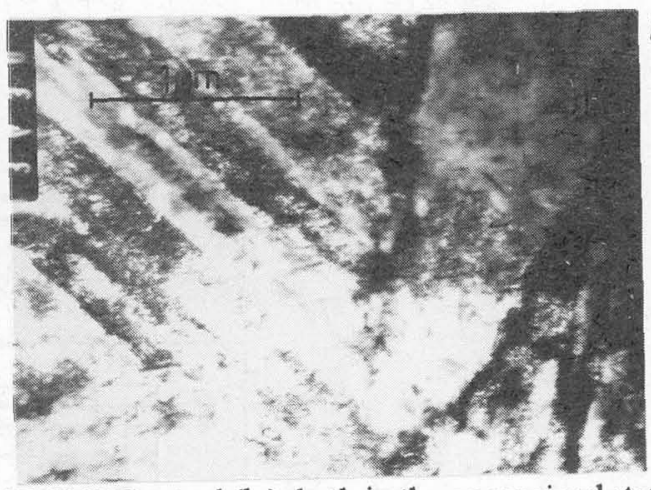

HNMBCu steel (b.), both in the as-received state.

Fig.1 Dislocation structure of 18G2A steel (a.) and 14HNMBCu steel (b.), both in the as-received b. a.
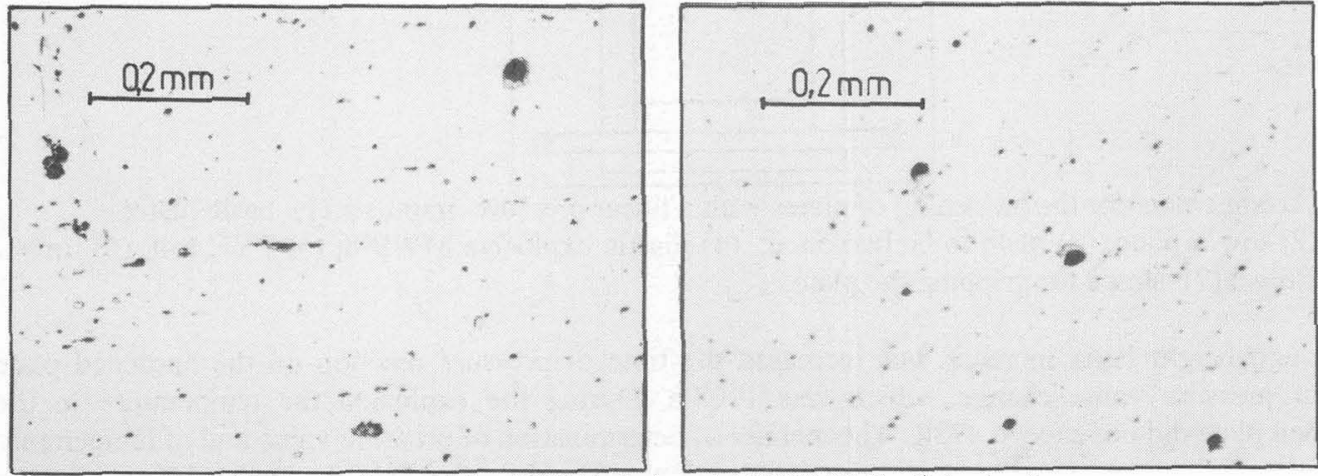

b.

Fig.2 The non-metallic inclusions of the 18G2A (a.) and 14HNMBCu (b.) steels .

was formed in the wooden frame the MWP-8 charge (4). The plates (2) and (3) and the foil (5) were placed in clamping rings and fastened in the different places of the base plate (1), which was made from the armour plate. The plate (2) was applied in order to protect the plate surface (1) against cumulative cavities. The foil PVC (5) protected the hardened plate against the thermal impact. The height of the explosive layer " $t$ " was changed in the range from 9 to $45 \mathrm{~mm}$. The increase of height more than $45 \mathrm{~mm}$ caused the devastation of hardened plates.

Table1. Chemical composition and mechanical properties of $18 \mathrm{G} 2 \mathrm{~A}$ and $14 \mathrm{HNMBCu}$ steels

\begin{tabular}{|c|c|c|c|c|}
\hline I & I 18G2A & & 4HNMBC & \\
\hline I Chemical composition (wt\%) & I & I & & \\
\hline I C & I 0.18 & I & 0.15 & I \\
\hline I $\mathbf{~ M n}$ & I 1.52 & I & 0.63 & \\
\hline I $\mathrm{Si}$ & 10.39 & I & 0.27 & \\
\hline I P & I 0.01 . & 1 & 0.005 & 1 \\
\hline IS & 10.012 & 21 & 0.013 & 1 \\
\hline I Cr & I traces & I & 0.54 & \\
\hline I Ni & I & I & 1 & 1 \\
\hline I Cu & I traces & $I$ & 0.26 & I \\
\hline I Mo & I & I & 0.46 & 1 \\
\hline I Mechanical properties & 1 & I & & 1 \\
\hline I Yield strength (MPa) & I 470 & I & 900 & \\
\hline I Ultimate tensile strength (MPa) & I 542 & I & 968 & 1 \\
\hline I Elongation (\%) & I 20 & 1 & 11 & 1 \\
\hline I Impact resistance $\left(\mathrm{kJ} / \mathbf{m}^{\wedge} 2\right)$ & I 637 & 1 & 722 & I \\
\hline
\end{tabular}




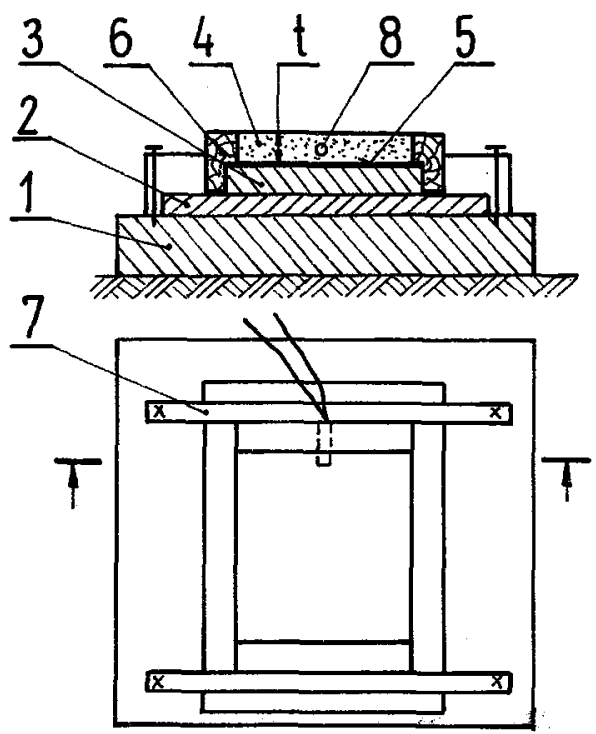

Fig.3 Arrangement for the hardening of plates with a linear pressure impulse: (1) basic plate;

(2) lower plate; (3) plate to be hardened; (4) plastic explosive MWP-8; (5) PVC foil; (6) timber frame; ( 7$)$ straps for gripping the plate.

Through height layer increase was increased the time of pressure reaction on the hardened plate without pressure value change, which was 19GPa. During the explosion the temperature in the hardened plate did not exceed 473K. The manner of determination of pressure value and of temperature was given in the paper $/ 5 /$. The maximum deformation received for the $18 \mathrm{G} 2 \mathrm{~A}$ steel $-15 \%$ and for the $14 \mathrm{HNMBCu}-12 \%$. The deformation in conventional hardening throughout the cold-rolling, lead in the comparative purpose, were changed in the range $3-80 \%$. The hardened plates were exposed to: the tensile test, Brinell hardness measurement and structural testing.

\section{Results and discussion}

Fig.4 illustrates the mechanical properties change of tested steels in the function of the plastic explosive MWP-8 layer height and plastic strain.

a)

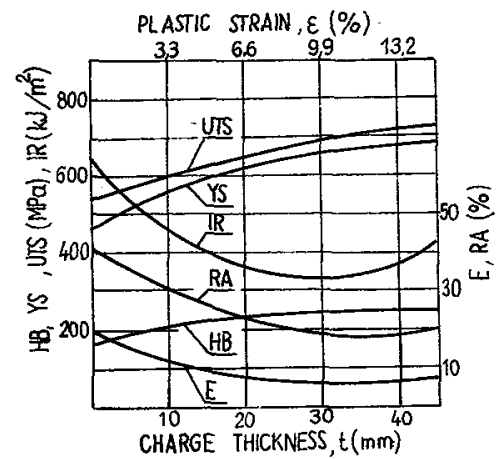

b)

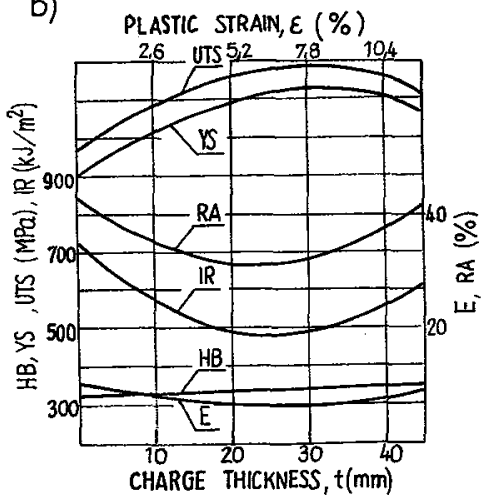

Fig.4 The changes of the mechanical properties of the 18G2A (a.) and 14HNMBCu (b.) steels hardened explosively.

The mechanical properties of the $18 G 2 \mathrm{~A}$ steel rise on an average $40 \%$ and the plastic properties 
lower about $58 \%$. For the $14 \mathrm{HNMBCu}$ steel these changes are 23 and $32 \%$ respectively. It points at the fact, that the hardening effect is closely connected with the hardened material and its initial state. The low-alloy steels with ferritic-pearlite structure have greater inclination to the hardening than the steels with the sorbitic structure.

The character of the mechanical properties changes is for both steels different. The $18 \mathrm{G} 2 \mathrm{~A}$ steel demonstrates the constant increase UTS, YS and HB proportionally to the degree of deformation. It seems, that the character of the curve UTS $=f(e)$ is similar to the stress-strain curve for monocrystals corresponding the II stage and the beginning of III stage. The presence of the grain boundary and accidental crystallographic orientation of grains eliminate the I stage of easy glide.

a.
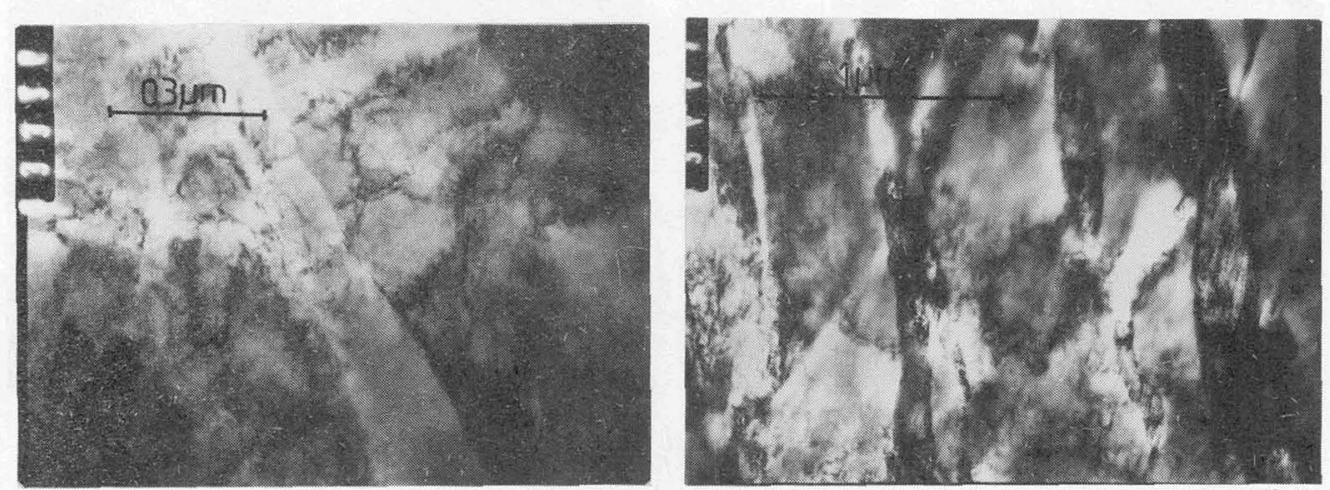

b.

Fig.5 The dislocation structure of the 18G2A hardened explosively steel: $\varepsilon=11.7 \%$ (a.), $\varepsilon=14.6 \%$ (b.).

The increase of the degree of deformation causes the growth of the cellular dislocation structure (Fig-5). The decrease of dislocation density observed in some grains, let admit, that the dynamic recovery and recrystallization take place in limit amount, but the influence of thermally activated processes on the mechanical properties is not visible. The $14 \mathrm{HNMBCu}$ steel shows extremum of the YS and HB at $\varepsilon=6.6-9.2 \%(\mathrm{t}=25-35 \mathrm{~mm})$ beyond this range the little decrease of these mechanical properties is stated. The character of the curve UTS=f( $\varepsilon$ ) shows the distinct occurrence of the II stage and especially III stage. The more clearly occurrence of the III stage in 14HNMBCu steel than in 18G2A steel can state, that such processes like: the dynamic recovery and recrystallization run more intensively in the 14HNMBCu steel than in 18G2A steel. The increase of the strain of the 14HNMBCu steel cause the distinct increase of the cellular dislocation structure and the reducing the dislocation density in some grains (Fig.6).

a.

b.
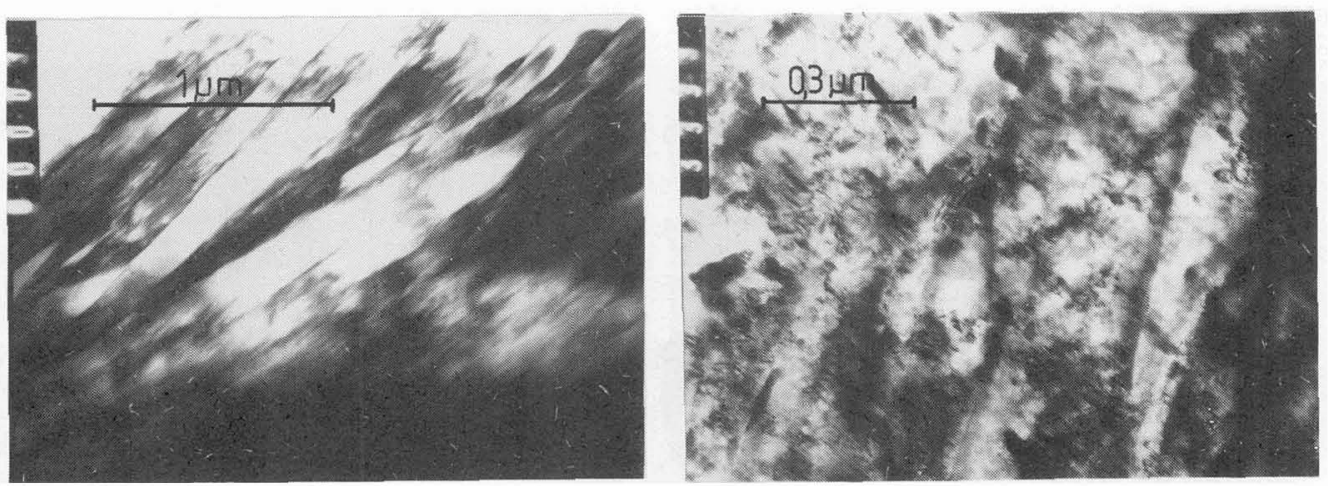

Fig. 6 The dislocation structure of the $14 \mathrm{HNMBCu}$ hardened explosively steel: $\varepsilon=9.5 \%$ (a.), $\varepsilon=11.8 \%$ (b.). 
The influence of thermal activated processes for this steel was greater than for $18 \mathrm{G} 2 \mathrm{~A}$. The greater tendency of the $14 \mathrm{HNMBCu}$ steel to the restoration of structure under the influence of plastic strain results probably from greater, in comparison with 18G2A steel stored energy, being the effect of initial heat treatment. However, from the other side the presence of non-metallic inclusions (Fig.2b), carbides of type ( $\mathrm{Fe}, \mathrm{Mn}) \mathrm{C}$, $(\mathrm{Fe}, \mathrm{Mn})_{3} \mathrm{C}$ and $\mathrm{M}_{23} \mathrm{C}_{6}$ (Fig-7) and dispersed cementite particles - promote the increase of dislocation density and make difficult the forming process of cellular dislocation structure.

a.
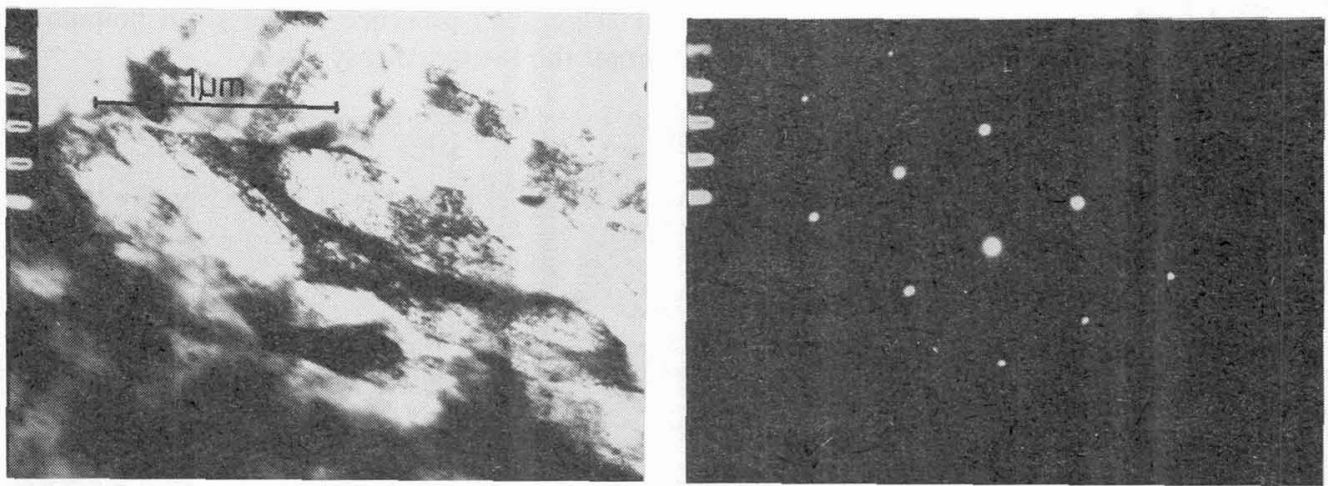

c.

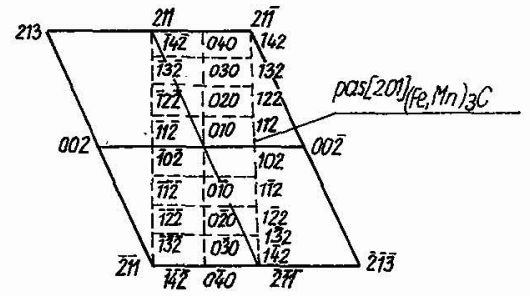

Fig.7 The dislocation structure of the $14 \mathrm{HNMBCu}$ steel: dislocation structure $\varepsilon=9.4 \%$ (a.), diffraction pattern (b.), solution of diffraction pattern (c.).

The presence of dissolved nitrogen and aluminium atoms and aluminium nitrites $(F$ ig. $8 b)$ in the $14 \mathrm{HNMBCu}$ steel, in accordance with the Lïcke-Detert theory, restrain the motion of grain boundary and the dynamic recrystallization. Taking into account the above mentioned, it was hardly to foresee, that the thermal activated processes will run easier and more intensively in the 14HNMBCu steel than in 18G2A steel.

a.
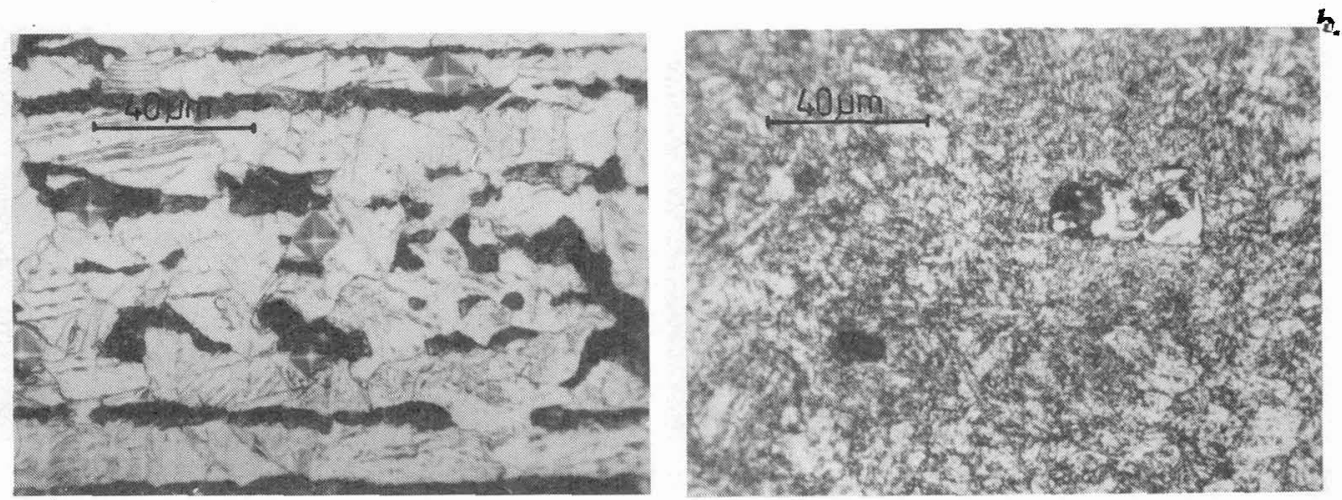

Fig. 8 The hardened explosively steel structure ( $\varepsilon=11.7 \%)$ : 18G2A (a.), 14HNMBCu (b.). 
The clear occurrence of slip lines were observed only in the explosive hardened 18G2A steel (Fig.8a). The slip lines are corrugated, thick and short and they are the shorter, the higher is the degree of deformation. The density of slip lines is high. The more distinct (Fig.8) slip lines observed in the dynamic hardened steel than in the static hardened steel $(F$ ig. 9 ) can be explained, by the fact that in the dynamic (explosive) hardened steel is activated a greater number of dislocation sources than in the static hardened steel. The testing of both steels has not show, despite the suggestions published in the papers $111,12,13 /$, that there are twins in the explosive hardened structure. The lack of twins is effected by the thickness of hardened plates, the obtained strain value and the hardened temperature. The dominant mechanism of deformation is the glide.

a.

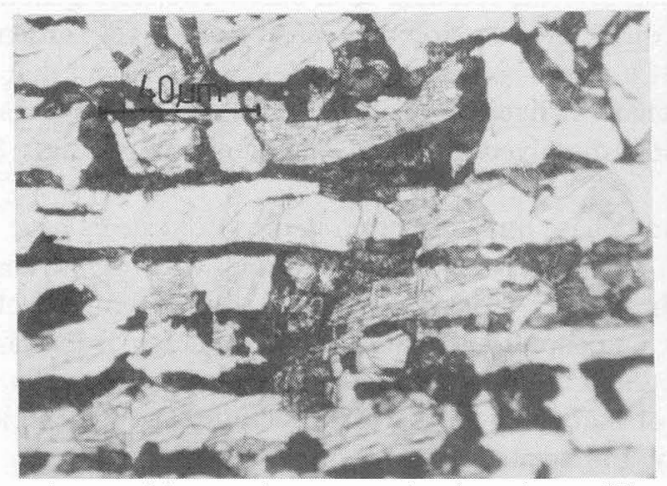

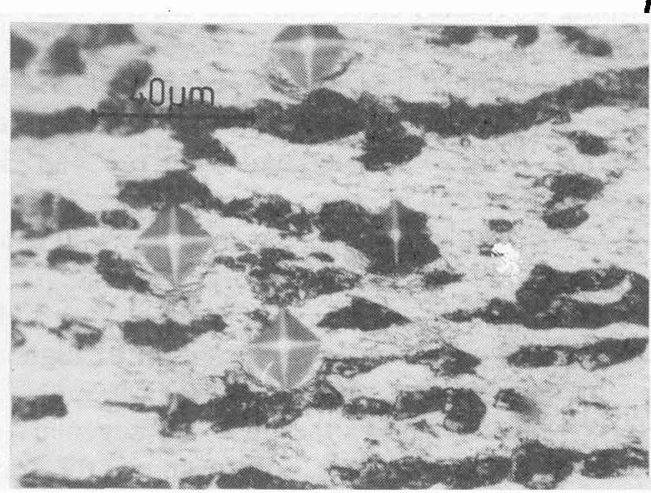

Fig. 9 The 18G2A steel structure hardened ( $\varepsilon=15 \%$ ): explosively (a.), cold-rolled (b.).

The pressure during the explosion of MWP-8 was evaluated on about $19 \mathrm{GPa}$, this in accordance with the papers $13,17 /$ should cause the participation of phase transformation in the hardening mechanism. Though the used structural testing was not satisfactory to this kind of investigation, on the ground of lack in diffraction patterns the slides of phases which have not been indicated in the structure before hardening can venture an opinion, that in the tested steels has not occurred the phase transformation.

a)
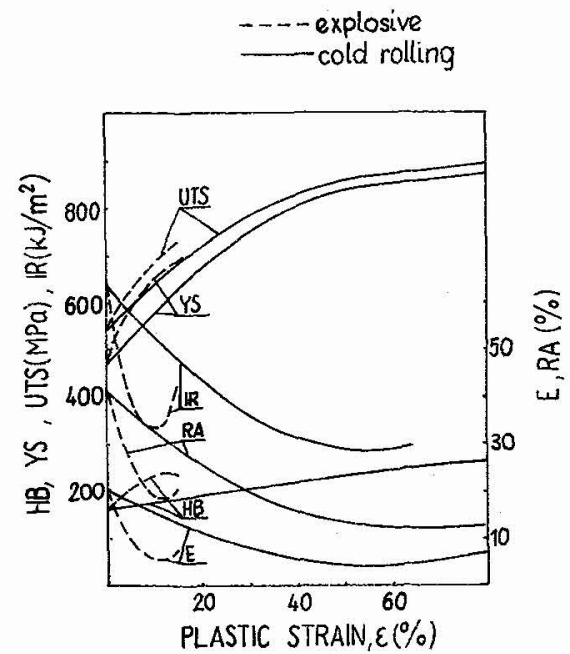

b)

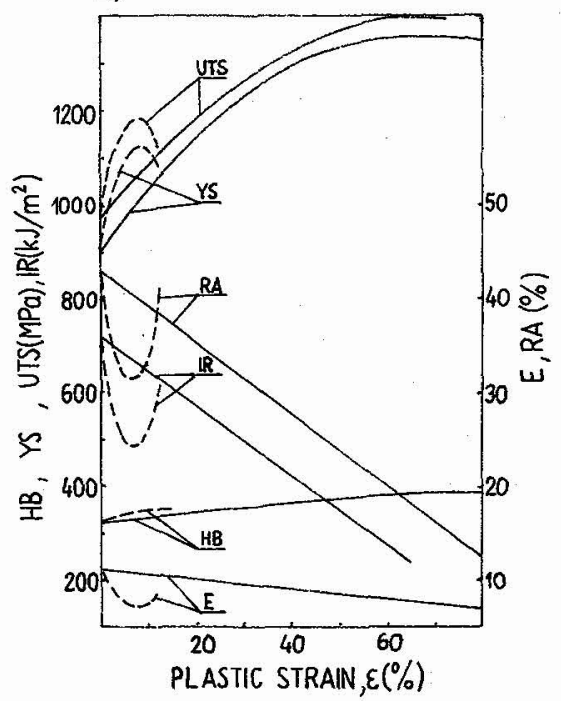

Fig.10 The changes of the mechanical properties of the 18G2A (a.) and 14HNMBCu (b.) steels explosively hardened and cold-rolled. 
The hardening through cold rolling let obtain the mechanical properties of tested materials exceeding the properties obtained as result of explosive hardening (Fig.1O). However by the same degree of strain materials hardened explosively obtain much more increase of strengthened properties than in the case of cold rolling. To obtain through the cold rolling the maximum strengthened properties of explosive hardened steel it should apply for the 18G2A-1.5 greater and for the 14HNMBCu-2.5 greater deformation.

\section{Conclusions}

The testing of two types of HSLA steel, explosively hardened has showed, that during explosive hardening of 18G2A steel, there are started many slip systems crossing each other. The arising LomerCottrell barriers are the effective obstacles for the dislocation motion and cause the distinct hardening without softening. The hardening of the $14 \mathrm{HNMBCu}$ steel should be connected with the fact that the movement of dislocations and grain boundary is made difficult through the presence of non-metallic inclusions, carbides, dispersive cementite particles, dissolved nitrogen and aluminium atoms and aluminium nitrites.

The hardening processes by way of twinning and phase transformation in the tested steels have not been observed. The reduction of hardening of $14 \mathrm{HNMBCu}$ steel is connected with the dynamic recovery and recrystallization. The steel shows the greater tendency to the restoration of defective structure. It is supposed to be the result of higher compared with 18G2A stored energy, what is the effect of initial heat treatment. In the tested steels there are the hard and soft regions. Especially the $14 \mathrm{HNMBCu}$ steel shows the great heterogeneity of hardening in the plate section. The soft regions were stated in these crystals, where came to the grain fragmentation.

\section{References}

11/ EZRA A. A.: Principles and practice of explosive metal working. Great Britain by the Gardan City Press Limited, Letchworth, Hertfordshire SGGIJS 1973.

2/ ERBEL S., KUCZYNSKI K., MARCINIAK Z.: Obrobka plastyczna. PWN, Warszawa 1986.

13/ BABUL W.: Odksztalcanie metali wybuchem. WNT, Warszawa 1980.

14/ STAUB F., ADAMCZYK J., CIESLAK L., GUBALA J., MACIEJNY A.: Metaloznawstwo. Wyd. Slask, Katowice 1979.

15/ GRONOSTAJSKI J., PALCZEWSKI W. I.: The effects of explosive hardening on the mechanical properties and structure of HSLA steels. Journal of Mechanical Working Technology, 18(1989)pp. 293-303.

16/ SESTAK B., LIBOVICKY S.: Symp. on the Relation Between Structure and Strength in Metals and Alloys, HMSO, London, (1963)pp. 157-77.

/7/ SESTAK B., LIBOVICKY S.: Czech. J. Phys., 13(1963)pp. 256-71.

18/ CAMPBELL. J.,D., DUBY J.: Proc. Conf. on Properties of Materials at High Rates of Strain, Inst. Mech. Eng. London, (1957)pp. 214-20.

19/ KVAM T., AUGLAND B.: High Energy Rate Working of Metals, Proc. NATO Advenced Study Instytute, Central Institute for Industrial Research, Oslo Norway, September,(1964)pp. 264-77.

110/WILLIAMS T.: Sheet Metal Indust., 39(1962)pp. 487-94.

/11/KRAMER K.,J.: source cited in Ref. 9,pp. 191.

/12/OTTO H.,E.: University of Denver, unpublished work, 1969.

/13/VERBRAAK C.,A.: Met. Progress, 83(1963) january, pp. 109-12.

/14/HOLLINGUM S.,W.: Austl. Inst. Metals, 12(1967)pp. 199-214.

/15/ROSENHAIN W., McMINN J.: Proc. Roy. Soc. (London) A108(1925) pp. 231-9.

/16/van WELY F.,E., VERBRAAK C.,A.: source cited in Ref. 9, pp. 172-93.

177BABUL W.: Umacnianie metali metodami udarowymi. Przeglad Mechaniczny, 21(1989)pp. 5-9. 